\title{
Gender and Personality Differences in the Self-Estimated Intelligence of Koreans
}

\author{
Wonjae Kang1, Adrian Furnham ${ }^{1,2}$ \\ ${ }^{1}$ Research Department of Clinical, Educational and Health Psychology, University College London, London, UK \\ ${ }^{2}$ Norwegian Business School (BI), Olso, Norway \\ Email: a.furnham@ucl.ac.uk
}

Received 29 April 2016; accepted 11 July 2016; published 14 July 2016

Copyright (C) 2016 by authors and Scientific Research Publishing Inc.

This work is licensed under the Creative Commons Attribution International License (CC BY).

http://creativecommons.org/licenses/by/4.0/

(c) (i) Open Access

\begin{abstract}
This study set out to examine gender and personality effects on self-estimated multiple intelligence. In all, 124 Koreans made self-estimates of 24 different kinds of intelligence. They also completed a short personality test. Results showed that males gave higher estimates than females on many different types of intelligence. Openness to experience, agreeableness and neuroticism were found to correlate with self-estimated intelligence. Income and education were also correlated with various self-estimated intelligence measures, but not overall self-estimated intelligence. The different intelligences factored into interpretable dimensions. Results were similar to those from different countries. Implications and limitations of the findings are discussed.
\end{abstract}

\section{Keywords}

Self-Estimated Intelligence, Gender, Personality, Social Class, Income

\section{Introduction}

Over the past decade there has been a great interest in Self-Estimated Intelligence (SEI) (Freund \& Kasten, 2012). There are at least three reasons for this. First, to help people with poor insight into their performance whose self-estimates are very different from their objective scores (Schlösser, Dunning, Johnson, \& Kruger, 2013). Second, to look at the individual differences and processes (like social desirability, hubris, and ability test experience) that lead to good and poor insight about abilities (Paulhus, 1986). Third, to assist ability selfawareness as it relates to career choice (Ackerman \& Wolman, 2007).

The studies are now international, including those from Austria (Stieger et al., 2010), Croatia (Bratko, Butkovic, Vukasovic, Chamorro-Premuzic, \& von Stumm, 2012), Germany (Ortner, Muller, \& Garcia-Retamero, 2011), the Netherlands (Bipp \& Kleingeld, 2012; Bipp, Steinmayr, \& Spinath, 2012), Russia (Furnham \& Sha- 
gabutdinova, 2012; Kornilova \& Novikova, 2012), and Spain (Perez, Gonzales, \& Beltran, 2010). One study compared self-estimates from twelve countries (von Stumm, Chamorro-Premuzic, \& Furnham, 2009). Further, they have been extended to issues like self-rated attention and concentration (Mengelkamp \& Jager, 2007).

Many studies have also investigated self-estimates of the "multiple intelligences" argued to be independent of each other. This study looks at self-estimates of overall and multiple intelligences from the perspective of three different researchers namely Gardner (1999), Sternberg (1997) and Cattell (1975) who each have different conceptions of intelligence. Gardner distinguishes between eight to ten, Sternberg three and Cattell ten types of intelligence which do not overlap very much and will each be used in this study.

Studies in this area have examined sex, as well as cultural, differences in self-estimates of ability (von Stumm, Makendrayogam, Chamorro-Premuzic, \& Furnham, 2009). Nearly all have demonstrated that males give higher estimates than females and that Africans and Americans give higher self-estimates than Europeans. Most studies done in Asia have shown the lowest self-estimates on all the types of intelligence rated. Some of these studies have also investigated participants' beliefs about intelligence (such as whether there are actual sex differences) and their personal experience of tests to examine whether these beliefs are related to self-estimates (Furnham \& Fukumoto, 2008).

Over thirty studies that used the "multiple" self-estimated intelligence model (Rammstedt \& Rammsayer, 2002) have found that gender differences were strongest on the Mathematical/Logical and Spatial intelligences, followed by overall ("g") and verbal intelligences, with males significantly overestimating and females significantly underestimating their abilities. A meta-analytical study investigating the magnitude of gender differences in mathematical/logical, spatial, overall and verbal self-estimated intelligences (Szymanowicz \& Furnham, 2013), found that the biggest weighted mean effect sizes were for Mathematical/Logical, $(d=.44)$, followed by Spatial $(d=.43)$, Overall $(d=.37)$ and Verbal $(d=.07)$ intelligence, with males providing higher estimates in all but verbal intelligence. Mathematical, spatial and verbal intelligences were the best predictors of self-estimated overall intelligence, as demonstrated through numerous multiple regression analyses (Furnham, 2001). Furnham (2000) proposed that people view intelligence as "male-normative", since mathematical/logical and spatial intelligences are areas where males are believed to excel (Storek \& Furnham, 2013).

\subsection{Current Study}

This study focuses on South Korea. There are some studies that focused on actual, psychometrically measured intelligence among Korean people (Lynn \& Song, 1994), but no studies appear to have been done on self-estimated intelligence. There are a few self-estimated intelligence studies which looked at people in Asian countries including China (Zhang \& Gong, 2001), Hong Kong (Yuen \& Furnham, 2005) and Japan (Furnham, Hosoe, \& Tang, 2001).

Studies have clearly demonstrated that people in Asia have different concepts of intelligence and self-evaluation strategies (Markus \& Kitayama, 1991; Niu \& Brass, 2011). Asians have a broader concept of intelligence compared to academic conceptions but less socio/emotional and more cognitive than Africans. Studies have also found that Chinese people tend to give more modest scores in self-estimated intelligence measures compared to Westerners (Zhang \& Gong, 2001), supporting the idea that how people perceive their intelligence is influenced, in part, by culture.

South Korea has been a male dominant society for a long time until recent years when women's status started to improve, as can been seen by the nation electing the woman president in 2013. It is possible that due to this national phenomenon, there may be an effect on how Korean people perceive of male and female differences in intelligence.

Following from previous studies, this study tested the following hypotheses:

H1: It is hypothesised that males will estimate their intelligence higher than females, especially in Overall, Mathematical/Logical, and Spatial intelligence.

H2: Extraversion, Openness and Conscientiousness will be positively related with Overall intelligence while Neuroticism and Agreeableness are negatively related with Overall intelligence.

\section{Method}

\subsection{Participants}

A total of 124 participants took part in the study. Participants were recruited on-line through email and web sites. 
The age range was 16 to 68 years with the mean age of $29.98(S D=12.79)$. There were 74 male and 51 female participants. All participants were born in South Korea, but some were living in different countries at the time of the survey. All participants had secondary education or higher education qualifications. They were asked to rate themselves on a 7-point religious scale $(1=$ Not at all to $5=$ Very $)(M=2.74, S D=3.24)$ and political beliefs $(1$ $=$ Strongly Right Wing to $7=$ Strongly Left Wing $)(M=3.90, S D=4.54)$.

\subsection{Materials}

Self-estimated intelligence. The study used a questionnaire which was developed by Furnham and his colleagues (Furnham, 2001) and had been used in many previous studies. The modified questionnaire asked participants to estimate 24 different intelligences which were defined by Gardner's theory of multiple intelligences (Gardner, 1999) and Sternberg's triarchic theory of intelligence (Sternberg, 1997) as well as Cattell-Horn-Carroll (CHC) theory of intelligence (Furnham \& Mansi, 2014; McGrew, 2005). The questionnaire also asked participants to estimate overall intelligence ("g").

At the beginning of the questionnaire, participants were given a fully described normal distribution of IQ curve which displayed scores of 100 as an "average” intelligence, 115 as "slightly high”, 130 as “high”, 145 as "very high", and 85 as "slightly low" and so on. They were also given a description of each item of multiple intelligences. It was then followed by a set of questions which asked about participants' beliefs about intelligence and intelligence tests which include six questions that are widely used in this area (Furnham \& Ward, 2001).

Ten-Item Personality Test (Gosling, Rentfrow, \& Swann, 2003). A brief measure of the big five personality trait was used. The questionnaire includes 10 items and measures the big five personality traits. Despite its inferiority compare to standard measures, Gosling et al. (2003) suggest that it has an adequate level of reliability and validity.

\subsection{Procedure}

The questionnaire was translated into Korean from English which then was translated back into English by an independent Korean-English speaker to verify the accuracy of the translation. The questionnaire was created using Google Documents, and was distributed online via email and postings on various web sites (e.g., Facebook). They were told that the task takes about 10 minutes to complete. Upon completion of the questionnaire, participants were debriefed with a short description about theories involved. Ethical permission was sought and given.

\section{Results}

\subsection{Gender Differences: Hypothesis One}

The data was analysed using MANOVA to see the gender difference in self-estimated intelligence. The mean values of each item for different gender are shown in Table 1. Males tended to rate themselves around .60 to .75 of a standard deviation above the mean and females around .3 to .60 above the mean. The overall intelligence showed a significant difference with male giving higher scores than females in estimating their intelligence. Similarly, males estimated higher than females in ten other intelligences; crystallised, fluid, quantitative reasoning, long-term memory and retrieval, decision/RT speed, spatial, logical/mathematical and spiritual intelligence. One large effect was found in long-term memory and retrieval and medium effects were found in overall, crystallised, quantitative reasoning and logical/mathematical intelligence (Cohen, 1988). Thus Hypothesis 1 was confirmed.

\subsection{Personality Differences: Hypothesis Two}

Correlations between the Big Five trait scores and intelligence estimates scores were computed (see Table 2). Neuroticism showed significant correlations with overall (.20), crystallised (.20), quantitative reasoning (.19) reading and writing ability (.24), visual processing (.19), processing speed (.23), spatial (.20) and practical intelligence (.20). Extraversion showed no significant correlations except for body kinaesthetic intelligence (.25) and creative intelligence (.25) which were positively correlated. Agreeableness was significantly correlated with Overall intelligence $(-.31)$ as well as crystallised (-.21), quantitative reasoning (-.25), processing speed (-.35) inter-personal (-20), emotional (-20) and practical intelligence (-.20). They all were negatively correlated except for inter-personal and emotional intelligence. Openness to experience was significantly correlated with all the self-estimated intelligences, especially fluid intelligence (.34) visual processing (.35) decision/reaction time/speed (.33) intra-personal (.41) existential (.33) spiritual intelligence (.33) and naturalistic intelligence (.36) 
Table 1. Mean of self-estimated intelligences for each gender.

\begin{tabular}{|c|c|c|c|}
\hline & $\begin{array}{c}\text { Males } \\
(n=74)\end{array}$ & $\begin{array}{l}\text { Females } \\
(n=50)\end{array}$ & $\mathrm{F}$ \\
\hline Overall intelligence & 115.21 & 108.57 & $5.78^{* * *}$ \\
\hline Crystallised intelligence & 112.68 & 107.70 & $7.15^{* * *}$ \\
\hline Fluid intelligence & 114.78 & 107.13 & $2.60^{*}$ \\
\hline Quantitative reasoning & 113.96 & 103.71 & $4.46^{* *}$ \\
\hline Reading and writing ability & 109.38 & 110.24 & 1.45 \\
\hline Short-term memory & 114.13 & 105.82 & 1.37 \\
\hline Long-term memory and retrieval & 108.44 & 105.50 & $8.83^{* * *}$ \\
\hline Visual processing & 112.12 & 106.59 & 2.26 \\
\hline Auditory processing & 107.65 & 101.70 & .37 \\
\hline Processing speed & 110.90 & 103.18 & 1.53 \\
\hline Decision/reaction time/speed & 110.91 & 103.56 & $3.30^{*}$ \\
\hline Verbal intelligence & 113.51 & 112.98 & 1.05 \\
\hline Spatial intelligence & 113.43 & 102.36 & $2.62^{*}$ \\
\hline Logical/mathematical intelligence & 112.42 & 99.12 & $5.02^{* *}$ \\
\hline Musical intelligence & 109.73 & 106.54 & 1.37 \\
\hline Body kinesthetic intelligence & 104.14 & 99.40 & .99 \\
\hline Inter-personal intelligence & 134.77 & 112.5 & .55 \\
\hline Intra-personal intelligence & 115.50 & 110.64 & 1.41 \\
\hline Existential intelligence & 114.26 & 110.68 & .65 \\
\hline Spiritual intelligence & 104.01 & 102.98 & $2.76^{*}$ \\
\hline Naturalistic intelligence & 105.11 & 106.32 & .08 \\
\hline Emotional intelligence & 109.51 & 112.34 & 1.61 \\
\hline Creative intelligence & 112.38 & 107.20 & 1.99 \\
\hline Practical intelligence & 115.57 & 107.92 & 2.29 \\
\hline
\end{tabular}

Note: ${ }^{*} p<.05, \stackrel{* *}{p}<.01$.

except for crystallised, long-term memory retrieval, processing speed, inter-personal and practical intelligence. All the significant estimations were positively correlated with openness to experience. Conscientiousness was significantly, and positively correlated with decision/reaction time/speed (.20), inter-personal (.23) and intrapersonal intelligence (.28). Not all aspects of Hypothesis two were confirmed.

\subsection{Factor Analysis}

The estimates of intelligence were then treated to a VARIMAX rotated factor analysis, to replicate the analysis procedure in most previous studies. The results are shown in Table 3. The first factor which accounted for over $50 \%$ of the variance had 13 "intelligences" loading on it and was labelled Cognitive Ability. The second which had 6 "intelligences" loading on it and which accounted for $10 \%$ of the variance was labelled as Humanistic Intelligence. The third factor had 4 items load upon it and was labelled Artistic Intelligence. 
Table 2. Correlations between the big five and self-estimated multiple intelligence.

\begin{tabular}{|c|c|c|c|c|c|}
\hline & $\begin{array}{l}\text { Neuroticism } \\
(n=124)\end{array}$ & $\begin{array}{l}\text { Extraversion } \\
(n=124)\end{array}$ & $\begin{array}{l}\text { Agreeableness } \\
\quad(n=124)\end{array}$ & $\begin{array}{l}\text { Openness } \\
(n=124)\end{array}$ & $\begin{array}{c}\text { Conscientiousness } \\
\quad(n=124)\end{array}$ \\
\hline Overall intelligence & $.201^{*}$ & .004 & $-.311^{* *}$ & $.226^{*}$ & .109 \\
\hline Crystallised intelligence & $.202^{*}$ & .004 & $-.214^{*}$ & .073 & .031 \\
\hline Fluid intelligence & .135 & .021 & -.174 & $.344^{* *}$ & .07 \\
\hline Quantitative reasoning & $.190^{*}$ & -.094 & $-.246^{* *}$ & $.220^{*}$ & .083 \\
\hline Reading \& writing ability & $.235^{* *}$ & .103 & -.148 & $.221^{*}$ & .033 \\
\hline Short-term memory & .151 & .072 & -.025 & $.210^{*}$ & .079 \\
\hline Long-term mem/retrieval & .111 & .059 & -.171 & -.030 & -.109 \\
\hline Visual processing & $.189^{*}$ & .063 & -.002 & $.346^{* *}$ & .125 \\
\hline Auditory processing & .165 & .049 & .039 & $.232^{* *}$ & .065 \\
\hline Processing speed & $.231^{* *}$ & -.065 & $-.350^{* *}$ & .138 & .091 \\
\hline Decision/reaction time & $.185^{*}$ & .072 & -.085 & $.330^{* *}$ & $.20^{*}$ \\
\hline Verbal intelligence & .036 & -.112 & -.140 & $.218^{*}$ & -.073 \\
\hline Spatial intelligence & $.204^{*}$ & -.022 & -.064 & $.278^{* *}$ & .027 \\
\hline Logical/mathematical IQ & .057 & -.032 & -.126 & $.202^{*}$ & .003 \\
\hline Musical intelligence & .155 & .173 & -.054 & $.248^{* *}$ & .085 \\
\hline Body kinesthetic IQ & .117 & $.246^{* *}$ & .099 & $.247^{* *}$ & .018 \\
\hline Inter-personal intelligence & .008 & .134 & $.199^{*}$ & .001 & $.178^{*}$ \\
\hline Intra-personal intelligence & .166 & .101 & -.079 & $.405^{* *}$ & $.227^{*}$ \\
\hline Existential intelligence & .130 & .090 & .085 & $.325^{* *}$ & .176 \\
\hline Spiritual intelligence & .022 & .147 & -.031 & $.368^{* *}$ & .154 \\
\hline Naturalistic intelligence & -.029 & .115 & .08 & $.364^{* *}$ & .09 \\
\hline
\end{tabular}

\subsection{Regressions}

Various regressions were performed. First, the regression considered demographic and ideological correlates of the factor scores (see Table 4). In the first two sets of variables namely demographic (sex, age, education) and ideology (religious and political beliefs) were predictor variable and the three factor scores were criterion variables. All were significant. Each had only one significant predictor score and the variance accounted for was between $6 \%$ and $14 \%$. Results indicated the only significant predictor of Cognitive Ability was gender (females gave lower estimates); the only significant indicator of Humanistic Intelligence was education showing those with less education gave lower scores; the only significant predictor of Artistic intelligence was political orientation (people with more left-wing beliefs gave higher estimates).

Second, personality and gender, were predictor variables and the factor scores were the criterion score (see Table 5). Two regressions were significant. The first, which accounted for $20 \%$ of the variance suggested that Open, Disagreeable, Neurotic males believed they had higher cognitive ability. The second, which accounted for $13 \%$ of the variance suggested that Open, Agreeable participants believed they had higher Humanistic Intelligence.

Table 6 shows three more regressions this time using Overall, fluid and crystallised intelligence as criterion variables and three sets of predictor variables: demographic (gender, age), beliefs (optimism, religiousness) and personality (the Big Five). The first analysis showed there were five significant predictors of Overall intelligence which accounted for $25 \%$ of the variance. Open, Disagreeable, Neurotic, right-wing males have higher self-estimates. There were only three significant predictors of Crystallised intelligence and they accounted for $16 \%$ of the variance. Neurotic, right-wing males gave higher self-estimates. There were only two predictors of Fluid intelligence which accounted for nearly a fifth of the variance: Open males gave higher scores. 
Table 3. Results of the VARIMAX rotated factor analysis.

\begin{tabular}{|c|c|c|c|}
\hline & \multicolumn{3}{|c|}{ Component } \\
\hline & Factor 1 & Factor 2 & Factor 3 \\
\hline Practical intelligence & .829 & .353 & .052 \\
\hline Fluid intelligence & .812 & .406 & .000 \\
\hline Processing speed & .798 & .087 & .194 \\
\hline Quantitative reasoning & .792 & .316 & .152 \\
\hline Crystallised intelligence & .787 & .191 & .273 \\
\hline Verbal intelligence & .769 & .226 & .196 \\
\hline Reading and writing ability & .763 & .394 & .002 \\
\hline Spatial intelligence & .761 & .397 & .010 \\
\hline Logical/mathematical intelligence & .738 & .253 & .136 \\
\hline Decision/reaction time & .679 & .497 & .155 \\
\hline Long-term storage and retrieval & .662 & .015 & .489 \\
\hline Short-term memory & .596 & .412 & .416 \\
\hline Visual processing & .511 & .480 & .475 \\
\hline Creative intelligence & .310 & .815 & .103 \\
\hline Naturalistic intelligence & .253 & .782 & .279 \\
\hline Emotional intelligence & .175 & .778 & .369 \\
\hline Existential intelligence & .268 & .721 & .358 \\
\hline Intra-personal intelligence & .473 & .682 & .261 \\
\hline Spiritual intelligence & .419 & .606 & .350 \\
\hline Inter-personal intelligence & -.217 & .227 & .786 \\
\hline Body kinaesthetic intelligence & .254 & .376 & .646 \\
\hline Auditory intelligence & .407 & .441 & .637 \\
\hline Musical intelligence & .524 & .339 & .556 \\
\hline Eigenvalue & 13.19 & 2.35 & 1.13 \\
\hline Variance (\%) & 57.33 & 10.23 & 4.89 \\
\hline
\end{tabular}

Table 4. Regression of the three factors onto the demographic and ideological scores.

\begin{tabular}{|c|c|c|c|c|c|c|}
\hline & \multicolumn{2}{|c|}{ Cognitive ability } & \multicolumn{2}{|c|}{ Humanistic intelligence } & \multicolumn{2}{|c|}{ Artistic intelligence } \\
\hline & Beta & $\mathrm{t}$ & Beta & $\mathrm{t}$ & Beta & $\mathrm{t}$ \\
\hline Gender & -.303 & $-3.40^{* *}$ & .150 & 1.72 & -.154 & -1.70 \\
\hline Age & -.086 & -.80 & .166 & 1.58 & -.047 & -.43 \\
\hline Education & .113 & -1.28 & -.338 & $-3.91^{* *}$ & .156 & 1.73 \\
\hline Political orientat. & -.164 & -1.65 & -.052 & -.53 & .270 & $2.66^{* *}$ \\
\hline Religiousness & -.192 & 1.82 & -.100 & -.97 & -.069 & -.64 \\
\hline$F(5,123)$ & \multicolumn{2}{|c|}{$3.65^{* *}$} & \multicolumn{2}{|c|}{$4.91^{* * *}$} & \multicolumn{2}{|c|}{$6.62^{*}$} \\
\hline Adjusted $\mathrm{R}^{2}$ & \multicolumn{2}{|c|}{.10} & \multicolumn{2}{|c|}{.14} & \multicolumn{2}{|c|}{.06} \\
\hline
\end{tabular}

Note: ${ }^{*} p<.05,{ }^{* *} p<.01,{ }^{* * *} p<.001$. 
Table 5. Regression with factor scores as criterion variable and traits as predictor factors.

\begin{tabular}{|c|c|c|c|c|c|c|}
\hline & \multicolumn{2}{|c|}{ Cognitive ability } & \multicolumn{2}{|c|}{ Humanistic intelligence } & \multicolumn{2}{|c|}{ Artistic intelligence } \\
\hline & Beta & $\mathrm{t}$ & Beta & $\mathrm{t}$ & Beta & $\mathrm{t}$ \\
\hline Gender & -.21 & $2.49^{* *}$ & .01 & .02 & .19 & 1.79 \\
\hline Extraversion & -.09 & 1.01 & .05 & .66 & .03 & 1.76 \\
\hline Agreeableness & -.27 & $3.31^{* * *}$ & .26 & $3.42^{* * *}$ & .04 & 1.16 \\
\hline Conscientiousness & -.13 & 1.48 & .15 & 1.84 & .04 & .39 \\
\hline Neuroticism & .26 & $2.90^{* *}$ & .00 & .11 & .04 & .33 \\
\hline Openness & .18 & $2.01^{*}$ & .50 & $6.28^{* * *}$ & .03 & .99 \\
\hline$F(6,123)$ & \multicolumn{2}{|c|}{$4.93^{* * * *}$} & \multicolumn{2}{|c|}{$11.11^{* * *}$} & \multicolumn{2}{|c|}{1.28} \\
\hline Adjusted $\mathrm{R}^{2}$ & \multicolumn{2}{|c|}{.20} & \multicolumn{2}{|c|}{.13} & \multicolumn{2}{|c|}{.01} \\
\hline
\end{tabular}

Note: ${ }^{*} p<.05,{ }^{* *} p<.01,{ }^{* * *} p<.001$.

Table 6. Regression of three intelligence estimates onto demographic, personality and other factors.

\begin{tabular}{|c|c|c|c|c|c|c|}
\hline & \multicolumn{2}{|c|}{ Overall intelligence } & \multicolumn{2}{|c|}{ Crystallised intelligence } & \multicolumn{2}{|c|}{ Fluid intelligence } \\
\hline & Beta & $\mathrm{t}$ & Beta & $\mathrm{t}$ & Beta & $\mathrm{t}$ \\
\hline Gender & -.305 & $3.70^{* *}$ & -.321 & $3.69^{* * *}$ & -.222 & $-2.59^{* *}$ \\
\hline Religiousness & -.069 & .85 & .091 & 1.06 & -.070 & -1.24 \\
\hline Political orientation & .164 & $2.01^{*}$ & .173 & $2.07^{*}$ & .117 & 1.31 \\
\hline Extraversion & .007 & .08 & .022 & .20 & -.047 & .87 \\
\hline Agreeableness & -.226 & $2.76^{* *}$ & -.172 & 1.99 & -.090 & -.54 \\
\hline Conscientiousness & .042 & .57 & .008 & .85 & -.017 & -.19 \\
\hline Neuroticism & .192 & $2.21^{*}$ & .183 & $2.04^{*}$ & .176 & 1.99 \\
\hline Openness & .225 & $2.61^{* *}$ & .085 & .92 & .372 & $4.14^{* * *}$ \\
\hline$F(8,115)$ & \multicolumn{2}{|c|}{$5.98^{* * *}$} & \multicolumn{2}{|c|}{$4.59^{* * *}$} & \multicolumn{2}{|c|}{$4.42^{* * *}$} \\
\hline Adjusted $\mathrm{R}^{2}$ & \multicolumn{2}{|c|}{.25} & \multicolumn{2}{|c|}{.16} & \multicolumn{2}{|c|}{.18} \\
\hline
\end{tabular}

Note: ${ }^{*} p<.05,{ }^{* *} p<.01,{ }^{* * *} p<.001$.

\section{Discussion}

As hypothesised, there was a significant gender effect in self-estimated intelligence. Males estimated their intelligence significantly higher than females in many intelligence measures including overall, crystallised and fluid intelligence as well as quantitative reasoning, short-term memory, long-term memory and retrieval, visual processing, spatial intelligence, logical/mathematical intelligence and practical intelligence. There were 3 to 15 points differences in self-estimated intelligence scores. The findings are consistent with studies done previously (Furnham, 2001), thus supporting the idea that the gender effect in self-estimated intelligence is universal. Indeed these results support studies done in countries as varied as Egypt, (Furnham \& Mottabu, 2004), Iran (Furnham, Shahidi, \& Baluch, 2007), Poland (Furnham, Wytykowska, \& Petrides, 2005) and South Africa (Furnham \& Akande, 2004).

None of female scores were significantly higher than males, which shows stronger "humility bias" than females in western countries, as studies done in other countries typically show higher ratings by males only on overall, mathematical and spatial intelligence (Furnham \& Chamorro-Premuzic, 2005; Rammstedt \& Rammsayer, 2002). Females scored higher on naturalistic and emotional intelligence, but they were not significant.

Although women's status is improving, it is still the case that men are still dominant in many areas in Korea such as business, education and government, and fewer women show exceptional success in these areas. This 
may suggest that people still believe males to outperform females, leading them to see men as superior than women. In South Korea, every man needs to join and serve in the army compulsorily for at least 22 months as a national service, where they experience a quick change in environment and learn practical skills. This may lead them to believe that they are better at adapting to different environment, which may have led to higher ratings in practical intelligence.

Unlike previous studies, the current study failed to replicate the gender difference in verbal intelligence (Estimation by males was only 1 point higher than females, and was not significant) (Szymanowicz \& Furnham, 2013). Although it is less common nowadays, there has been a social norm that "quiet men" are more desirable in Korea. This could have led participants to believe that males are less expressive and articulate than females in other cultures.

\subsection{Personality Difference}

Following the previous studies, the current study hypothesised Extraversion, Openness and Conscientiousness to be positively related, while Neuroticism and Agreeableness to be negatively related to higher ratings of general intelligence. However, the current study failed to replicate previous studies particularly for Neuroticism. Openness to experience was positively correlated while Agreeableness was negatively correlated with self-rated intelligence as predicted, but Neuroticism was unexpectedly positively correlated with self-estimates. Openness to experience was positively correlated with all the intelligences except crystallised, long-term memory and retrieval, processing speed, inter-personal and practical intelligence. Agreeableness was correlated with seven intelligence measures which all were negatively correlated except two intelligences which were emotional intelligence and inter-personal intelligence. Neuroticism was significantly correlated with nine intelligence measures which all were positively correlated. Although not correlated with overall intelligence, Extraversion and Conscientiousness showed correlations with some intelligence measures, as Extraversion was correlated with body kinaesthetic and creative intelligence while Conscientiousness was correlated with decision/reaction time/speed, inter and intra-personal intelligence.

What is most interesting in these results is perhaps positive relationship between Neuroticism and self-estimated intelligence. Many studies found that Neuroticism is negatively correlated with both self-estimated and actual psychometric intelligence, but this study found the opposite. The argument is not that Neurotics are less intelligent than stable individual but that their anxiety has a negative impact on test performance and makes them doubt their own ability. However, one possible explanation to this is the high level of stress in Korea and the elevated scores. It is possible that the back translation of the items had a special meaning in Korea and this merits further investigation.

The factor analysis shown in Table 2 replicates various other studies which suggests that lay people distinguish between the (real) academic intelligences and the social intelligences. Thus the three Gardener academic intelligences (mathematical, spatial, verbal) loaded on the same factor as the Cattellian factors which are level II factors (Furnham \& Mansi, 2014). In this study, the social intelligences split into two with one factor being clearly linked to the arts involving dance and music. In this sense, lay people are not unlike orthodox intelligence researchers who distinguish between cognitive abilities (measured by timed, power tests) and social abilities (measured by untimed preference) tests.

\subsection{The Regressions}

The results of the study have a few, but important theoretical and practical implications. It provides an additional support for strong gender difference with less cultural variance in self-estimated intelligence. Practically, it provides an explanation to gender discrimination that still exists nowadays such as glass ceiling effect for women in workplaces, which is often overlooked and ignored. As both men and women often estimate women's intelligence less than men (Furnham, 2005), it is possible that women will be disadvantaged when other people evaluate their work hence causing slower progression and promotion in workplaces.

Despite some correlations and regressions found, there were limitations to this study. This study only looked at how self-estimated intelligence is related to gender and personality but not actual, psychometrically measured intelligence. This leaves the relationship between self-estimated intelligence and actual intelligence unanswered. It might have been the case that either males or females have realistic perception on their intelligence and the other gender estimates their intelligence higher or lower than the actual intelligence. 


\section{References}

Ackerman, P., \& Wolman, S. (2007). Determinants and Validity of Self-Estimates of Ability and Self-Concept Measures. Journal of Experimental Psychology: Applied, 13, 57-78. http://dx.doi.org/10.1037/1076-898x.13.2.57

Bratko, D., Butkovic, A., Vukasovic, T., Chamorro-Premuzic, T., \& Von Stumm, S. (2012). Cognitive Ability, Self-Assessed Intelligence and Personality: Common Genetic but Independent Environmental Aetiologies. Intelligence, 40, 91-99. http://dx.doi.org/10.1016/j.intell.2012.02.001

Bipp, T., \& Kleingeld, A. (2012). Self-Estimates of Intelligence: Interaction Effects of the Comparison to a Specific Reference Group and Neuroticism 1. Psychological Reports, 110, 403-415. http://dx.doi.org/10.2466/04.07.09.PR0.110.2.403-415

Bipp, T., Steinmayr, R., \& Spinath, B. (2012). A Functional Look at Goal Orientations: Their Role for Self-Estimates of Intelligence and Performance. Learning and Individual Differences, 22, 280-289. http://dx.doi.org/10.1016/j.lindif.2012.01.009

Cattell, R. B., \& Child, D. (1975). Motivation and Dynamic Structure. Holt, Rinehart and Winston.

Cohen, J. (1988). Statistical Power Analysis for the Behavioral Sciences (2nd ed.). Hillsdale, NJ: Erlbaum.

Freund, P. A., \& Kasten, N. (2012). How Smart Do You Think You Are? A Meta-Analysis on the Validity of Self-Estimates of Cognitive Ability. Psychological Bulletin, 138, 296. http://dx.doi.org/10.1037/a0026556

Furnham, A. (2001). Self-Estimates of Intelligence: Culture and Gender Difference in Self and Other Estimates of Both General (g) and Multiple Intelligences. Personality and Individual Differences, 31, 1381-1405. http://dx.doi.org/10.1016/S0191-8869(00)00232-4

Furnham, A. (2005). Gender and Personality Differences in Self- and Other Ratings of Business Intelligence. British Journal of Management, 16, 91-103. http://dx.doi.org/10.1111/j.1467-8551.2005.00434.x

Furnham, A., \& Akande, A. (2004). African Parents' Estimates of Their Own and Their Children’s Multiple Intelligences. Current Psychology, 22, 281-294. http://dx.doi.org/10.1007/s12144-004-1034-X

Furnham, A., \& Chamorro-Premuzic, T. (2005). Estimating One’s Own and One’s Relatives’ Multiple Intelligence: A Study from Argentina. Spanish Journal of Psychology, 8, 12-20. http://dx.doi.org/10.1017/S1138741600004911

Furnham, A., \& Fukumoto, S. (2008). Japanese Parents' Estimates of Their Own and Their Children’s Multiple Intelligences: Cultural Modesty and Moderate Differentiation. Japanese Psychological Research, 50, 63-76. http://dx.doi.org/10.1111/j.1468-5884.2008.00362.x

Furnham, A., Hosoe, T., \& Tang, L. P. (2001). Male Hubris and Female Humility? A Cross-Cultural Study of Ratings of Self, Parental and Sibling Multiple Intelligence in America, Britain and Japan. Intelligence, 30, 101-115. http://dx.doi.org/10.1016/S0160-2896(01)00080-0

Furnham, A., \& Mansi, A. (2014). The Self-Assessment of the Cattell-Horn-Carroll Broad Stratum Abilities. Learning and Individual Differences, 32, 233-237. http://dx.doi.org/10.1016/j.lindif.2014.03.014

Furnham, A., \& Mottabu, R. (2004). Sex and Culture Differences in Estimates of General and Multiple Intelligence: A Study Comparing British and Egyptian Students. Individual Differences Research, 2, 82-96.

Furnham, A., \& Shagabutdinova, K. (2012). Sex Differences in Estimating Multiple Intelligences in Self and Others: A Replication in Russia. International Journal of Psychology, 47, 448-459. http://dx.doi.org/10.1080/00207594.2012.658054

Furnham, A., Shahidi, S., \& Baluch, B. (2007). Sex and Cultural Differences in Perceptions of Estimated Multiple Intelligences for Self and Family: A British-Iranian Comparison. Journal of Cross-Cultural Psychology, 33, 270-285. http://dx.doi.org/10.1177/0022022102033003004

Furnham, A., Wytykowska, A., \& Petrides, K. V. (2005). Estimates of Multiple Intelligences: A Study in Poland. European Psychologist, 10, 51-59. http://dx.doi.org/10.1027/1016-9040.10.1.51

Furnham, A., \& Ward, C. (2001). Sex Differences, Test Experience and the Self-Estimation of Multiple Intelligence. New Zealand Journal of Psychology, 30, 52-59.

Gardner, H. (1999). Intelligence Reframed: Multiple Intelligences for the 21st Century. New York: Basic Books.

Gosling, S. D., Rentfrow, P. J., \& Swann, W. B. (2003). A Very Brief Measure of the Big-Five Personality Domains. Journal of Research in Personality, 37, 504-528. http://dx.doi.org/10.1016/S0092-6566(03)00046-1

Kornilova, T. V., \& Novikova, M. A. (2012). Self-Assessed Intelligence, Personality, and Psychometric Intelligence: Preliminary Validation of a Model with a Selected Student Population. Psychology in Russia: State of the Art, 5.

Lynn, R., \& Song, M. J. (1994). General Intelligence, Visuospatial and Verbal Abilities in Korean Children. Personality and Individual Differences, 16, 363-364. http://dx.doi.org/10.1016/0191-8869(94)90177-5

Markus, H., \& Kitayama, S. (1991). Culture and the Self: Implications for Cognition, Emotion, and Motivation. Psychological Review, 98, 224-253. http://dx.doi.org/10.1037/0033-295X.98.2.224 
McGrew, K. S. (2005). The Cattell-Horn-Carroll (CHC) Theory of Cognitive Abilities: Past, Present and Future. In D. Flanagan, \& Harrison (Eds.), Contemporary Intellectual Assessment: Theories, Tests, and Issues (2nd ed., pp. 136-202). New York: Guilford Press.

Mengelkamp, C., \& Jager, R. S. (2007). Self-Estimates of Attention Performance. Psychology Science, 49, $223-237$.

Niu, W., \& Brass, J. (2011). Intelligence in Worldwide Perspective. In R. J. Sternberg, \& S. B. Kaufman (Eds.), Cambridge Handbook of Intelligence (pp. 623-646). New York: Cambridge University Press. http://dx.doi.org/10.1017/cbo9780511977244.032

Ortner, T. M., Müller, S. M., \& Garcia-Retamero, R. (2011). Estimations of Parental and Self Intelligence as a Function of Parents' Status: A Cross-Cultural Study in Germany and Spain. Social Science Research, 40, 1067-1077. http://dx.doi.org/10.1016/j.ssresearch.2011.03.006

Rammstedt, B., \& Rammsayer, T. (2002). Self-Estimated Intelligence: Gender Differences, Relationship to Psychometric Intelligence and Moderating Effects of Level of Education. European Psychologist, 7, 275-284. http://dx.doi.org/10.1027//1016-9040.7.4.275

Paulhus, D. L. (1986). Self-Deception and Impression Management in Test Responses. In A. Angleitner, \& J. S. Wiggins (Eds.), Personality Assessment via Questionnaires (pp. 143-165). Berlin: Springer. http://dx.doi.org/10.1007/978-3-642-70751-3 8

Perez, L., Gonzalez, C., \& Beltran, J. (2010). Parental Estimates of Their Own and Their Relatives’ Intelligence. A Spanish Replication. Learning and Individual Differences, 20, 669-676. http://dx.doi.org/10.1016/j.lindif.2010.09.005

Schlösser, T., Dunning, D., Johnson, K. L., \& Kruger, J. (2013). How Unaware Are the Unskilled? Empirical Tests of the "Signal Extraction" Counterexplanation for the Dunning-Kruger Effect in Self-Evaluation of Performance. Journal of Economic Psychology, 39, 85-100. http://dx.doi.org/10.1016/j.joep.2013.07.004

Sternberg, R. J. (1997). A Triarchic View of Giftedness: Theory and Practice. In N. Coleangelo, \& G. A. Davis (Eds.), Handbook of Gifted Education (pp. 43-53). Boston, MA: Allyn and Bacon.

Stieger, S., Kastner, C. K., Voracek, M., von Stumm, S., Chamorro-Premuzic, T., \& Furnham, A. (2010). Independent Effects of Personality and Sex of Self-Estimated Intelligence. Psychological Reports, 107, 553-563. http://dx.doi.org/10.2466/04.07.09.PR0.107.5.553-563

Storek, J., \& Furnham, A. (2013). Gender, “ $g$ ”, and Fixed versus Growth Intelligence Mindsets as Predictors of Self-Estimated Domain Masculine Intelligence (DMIQ). Learning and Individual Differences, 25, 93-98. http://dx.doi.org/10.1016/j.lindif.2013.03.007

Szymanowicz, A., \& Furnham, A. (2013). Gender and Gender Role Differences in Domain-Masculine Intelligence and Beliefs about Intelligence. Journal of Social Psychology, 153, 399-423. http://dx.doi.org/10.1080/00224545.2012.754397

Yuen, M., \& Furnham, A. (2005). Sex Differences in Self-Estimation of Multiple Intelligences among Hong Kong Chinese Adolescents. High Ability Studies, 16, 187-199. http://dx.doi.org/10.1080/13598130600618009

Von Stumm, S., Chamorro-Premuzic, T., \& Furnham, A. (2009). Decomposing Self-Estimates of Intelligence: Structure and Gender Differences across 12 Nations. British Journal of Psychology, 100, 429-442. http://dx.doi.org/10.1348/000712608X357876

Zhang, Y., \& Gong, Y. (2001). Self-Estimated Intelligence and Its Related Factors. Chinese Journal of Clinical Psychology, 9, 193-195. 


\section{Submit or recommend next manuscript to SCIRP and we will provide best service for you:}

Accepting pre-submission inquiries through Email, Facebook, LinkedIn, Twitter, etc.

A wide selection of journals (inclusive of 9 subjects, more than 200 journals)

Providing 24-hour high-quality service

User-friendly online submission system

Fair and swift peer-review system

Efficient typesetting and proofreading procedure

Display of the result of downloads and visits, as well as the number of cited articles

Maximum dissemination of your research work

Submit your manuscript at: http://papersubmission.scirp.org/ 